\title{
Origin and Remediation of Melanoidin Contamination in Water Sources
}

\author{
Ranjan Singh $^{1} *$, Tanim Arpit Singh ${ }^{2}$, Trashi Singh ${ }^{3}$, Rajeeva Gaur ${ }^{4}$, \\ Prabash Kumar Pandey ${ }^{5}$, Farrukh Jamal ${ }^{6}$, Shikha Bansal ${ }^{7}$, Laxmi Kant Pandey ${ }^{8}$, \\ Surendra Sarsaiya ${ }^{9}$, Jitendra Nagpure ${ }^{10}$, Saket Mishra ${ }^{11}$, Manogya Kumar Gaur ${ }^{12}$, \\ Priyanka Gupta $^{7}$, Priyanka Uikey ${ }^{7}$, Subhendra K. Patel $^{7}$ and Rakhi Patel ${ }^{7}$ \\ ${ }^{1}$ Choithram College of Professional Studies, Indore (M.P.), India \\ ${ }^{2}$ Department of Biosciences, Maharaja Ranjit Singh College of Professional Sciences, \\ Indore (M.P.), India \\ ${ }^{3}$ Cyanobacterial Research Lab, Rani Durgavati University, Jabalpur (M.P.), India \\ ${ }^{4}$ Department of Microbiology, ${ }^{6}$ Department of Biochemistry, \\ Dr. R.M.L. Avadh University, Ayodhaya (U.P.), India \\ ${ }^{5}$ Department of Biochemistry, Allahabad University (U.P.), India \\ ${ }^{7}$ Department of Botany and Microbiology, ${ }^{8}$ Department of Biotechnology, \\ St. Aloysius College Autonomous, Jabalpur (M.P.), India \\ ${ }^{9}$ Zunyi Medical University, China \\ ${ }^{10}$ Mycology Research Lab, Rani Durgavati University, Jabalpur (M.P.), India \\ ${ }^{11}$ Madhya Pradesh Pollution Control Board, Bhopal (M.P.), India \\ ${ }^{12}$ Balrampur Sugar Mill, Balrampur (U.P.), India
}

*Corresponding author

\begin{abstract}
Keywords
Spent wash,

Distillery,

Wastewater,

Melanoidin

Article Info

Accepted:

12 January 2019

Available Online:

10 February 2019 from distilleries, fermentation industries, sugar mills, pharmaceutical companies and other molasses based industries are also responsible for contamination and generation of waste water. The distillery waste water contains dark brown colored recalcitrant compounds collectively termed as melanoidin polymers. These polymers cause oxygen depletion and increase BOD. In soil they reduce the soil alkalinity and manganese availability, inhibit seed germination and affect vegetation. The distillery wastewater poses a serious threat to water quality in several regions of the country. Its disposal on land is equally detrimental causing a reduction in soil alkalinity and inhibition of seed germination. The conventional methods of water treatment fail to remove melanoidin. There is thus an urgent need to control and remediate the melanoidin contamination and in current perspective microorganisms have proved to be an efficient scavenger. They have shown tremendous ability to utilize melanoidin as their source of nutrition and remediate the polluted water. The microbial approach for treatment of melanoidin contamination seems to be the solution over the conventional methods that fail to remove the contamination of pigment.
\end{abstract}

A B S T R A C T

Distillery is one of the most highly polluting and growth oriented industries in India with reference to the extent of water pollution and the quantity of wastewater generated. Apart 


\section{Introduction}

Molasses from sugarcane industry is a common raw material used in ethanol production due to its easy availability and low cost (Kalavathi et al., 2001). India is the second largest producer of ethanol in Asia. There are 319 distilleries in India with an installed capacity of 3.25 billion liter of alcohol (Uppal, 2004; Tewari et al., 2007). According to the Central Pollution Control Board (CPCB), Government of India, distillery is the topmost polluting industries of India. For every one liter of alcohol produced, 10-15 liter of spent wash is generated and a typical distillery producing ethanol from cane molasses generates nearly half million liters of spent wash daily (Ghosh et al., 2002; Kumar et al., 1998). Approximately, 40 billion liters of spent wash is generated annually in India alone for the production of 2.3 billion liters of alcohol. The population equivalent of distillery waste based on BOD has been reported to be as high as 6.2 billion, which means that the contribution of distillery waste in India to organic pollution is approximately seven times more than the contribution by the entire population (Kanimozhi and Vasudevan, 2010).

The distillery waste water contain dark brown colored recalcitrant compounds collectively termed as melanoidin polymers which are the product of maillard reaction between the amino acids and carbonyl groups present in molasses (Wedzicha and Kaputo, 1992). These effluents are hazardous when released in water bodies as they cause oxygen depletion and increase BOD. In soil they reduces the soil alkalinity and manganese availability, inhibit seed germination and affect vegetation. Besides causing unaesthetic discoloration of water and soil, melanoidin pigments are also toxic to microorganisms in soil and water (Mohana et al., 2007). Dark brown color of this effluent is highly resistant to microbial degradation and other biological treatment. Melanoidins are recalcitrant compounds thus the conventional treatment methods are not effective for complete color removal. The color can even increase during anaerobic treatments, due to repolymerization of compounds (Satyawali and Balakrishnan, 2007). Anaerobic digestion of effluents produces dark brown sludge which is used as fertilizer and the colored water is discharged after diluting it several folds with water.

The spent wash has an extremely high Chemical Oxygen Demand (COD) load and contains high percentage of dissolved organic and inorganic matter. Apart from high organic content, distillery wastewater also contains nutrients in the form of nitrogen, phosphorous and potassium that can lead to eutrophication of waste bodies. Spent wash disposal even after conventional treatment is hazardous and has a high pollution potential due to the accumulation of non-biodegradable recalcitrant compounds, which are mostly colored and in a highly complex state. Melanoidin have anti-oxidant properties causing toxicity to many microorganisms involved in waste water treatment processes (Sirianuntapiboon et al., 2004). Lowering of $\mathrm{pH}$ value of the streams, increasing organic load and obnoxious smell are some of the major problems caused due to distillery wastewater. In addition to pollution, increasingly stringent environmental regulations are forcing distilleries to improve existing treatment and also explore alternative methods for effluent management (Kanimozhi and Vasudevan, 2010).

\section{Alcohol manufacturing from sugar molasses}

The first distillery in the country was setup at Kanpur, Uttar Pradesh, India in 1805 by Carew \& Co. Ltd., for manufacture of Rum 
for the army. The technique of fermentation, distillation and blending of alcoholic beverages was developed in India on the lines of practices adopted overseas particularly in Europe. Alcohol can be produced from a wide range of feedstock. These include sugar-based (Sugarcane and beet molasses, cane sugar juice), starch-based (corn, wheat, cassava, rice, barley) and cellulosic (crop residues, sugarcane bagasse, wood, municipal solid wastes) material. The production of alcohol in distilleries based on sugarcane molasses constitutes a major industry in Asia and South America. The world's total production of alcohol from sugarcane molasses is more than 13 million $\mathrm{m}^{3} /$ year. The distillery industry today consists broadly of two parts, potable liquor and the industrial alcohol. The potable distillery producing Indian made foreign liquor and country liquor has a steady but limited demand with growth rate of about 710 percent per annum (Satyawali and Balakrishan, 2008).

\section{Wastewater characteristics}

Distillery effluent is reported as medium to high-strength organic wastewater. Generally the effluents term as (spent wash, stillage, slop or vinasse) from molasses based distilleries are acidic and contain large amount of dark brown colored molasses wastewater (MWW). The characteristic of the effluent depend on the raw material used also, it is estimated that $88 \%$ of the molasses constituents end up as waste (Jain et al., 2002).

In addition, cane molasses effluent (spent wash) contains low molecular weight compounds such as lactic acid, glycerol, ethanol and acetic acid (Wilkie et al., 2000). In general, distillery wastewaters are acidic, have a brown color and have a high content of organic substances that varies according to the raw material distilled e.g. wine type, lees etc. (Bustamante et al., 2005; Keyser et al., 2003). Distillery wastewaters are acidic and their high organic content can cause considerable environmental pollution (Keyser et al., 2003).

The distillery wastewater is recalcitrant, owing to the presence of melanoidin, contributes color to the effluent. These compounds show antioxidant properties and are inhibitory to treatment process. An average composition of sugarcane molasses based distillery effluent from India has been described (Singh and Nigam, 1995). Cane molasses also contains around $2 \%$ of a dark brown pigment called melanoidin that impart color to the effluent (Kalavathi et al., 2001). Melanoidins are low and high molecular weight polymers formed as one of the final products of Maillard reaction, which is a nonenzymatic browning reaction resulting from the reaction of reducing sugars and amino compounds. This reaction proceeds effectively at temperatures above $50^{\circ} \mathrm{C}$ and $\mathrm{pH}$ 4-7. The structure of melanoidin is still not known. Only 6-7\% degradation of the melanoidin is achieved in the conventional anaerobic - aerobic effluent treatment process (Gonzalez et al., 2000). Due to their antioxidant properties, melanoidin are toxic to many microorganisms involved in wastewater treatment (Sirianuntapiboon et al., 2004). Apart from melanoidins, distillery effluent contains other colorants such as phenolics, caramel and melanin. Phenolics are more pronounced in cane molasses wastewater whereas melanin is significant in beet molasses (Godshall, 1999). In addition to these, organic acids, alcohol, hexose sugars and soluble proteins are also found (Keyser $e t$ al., 2003). Polyphenol concentrations in distillery wastewater vary considerably and can range from 29-474 mg/1 (Bustamante et al., 2005). Polyphenols are responsible for strong inhibitory effects on microbial activity, must be removed during wastewater treatment 
as they pose environmental and public health risks. Humans exposed to phenol at 1300 $\mathrm{mg} / \mathrm{L}$ of concentration exhibits significant increases in diarrhea, dark urine, mouth sores and burning of the mouth (Collins et al., 2005).

\section{Colorants in distillery wastewaters}

The molasses effluent from alcoholic fermentation has large amount of brown pigment. During anaerobic treatments, and due to re-polymerization, brown color in the molasses effluent is hardly degraded. It is also increased during the conventional treatments. Phenolics (tannic and humic acids) from the feedstock, melanoidins from Maillard reaction of sugars (carbohydrates) with proteins (amino groups), caramels from overheated sugars, and furfurals from acid hydrolysis mainly contribute to the colour of the effluent (Kort, 1979). During heat treatment, the Maillard reaction (non enzymatic reaction) takes place accompanied by formation of a class of compounds known as Maillard products. The reaction proceeds effectively at $>50^{\circ} \mathrm{C}$ and it is favored at $\mathrm{pH}$ 4-7 (Morales and Jimnez- Perez, 2001).

Melanoidins are one of the final products of the Maillard reaction. They are complex compounds with their structures not fully understood. Melanoidins have antioxidant properties, which render them toxic to aquatic micro and macroorganisms (Kitts et al., 1993). Melanoidins or related formation products can occur in different processes of beverage manufacture, such as heat concentrated juices and musts, beers or wines. From studies using ${ }^{13} \mathrm{C}$ and ${ }^{15} \mathrm{~N}$ CP-NMR spectrometry, (Hayase et al., 1986) confirmed the presence of olefinic linkages and conjugated enamines which were suggested to be important for the structure of the chromophores in melanoidin. For melanoidins formed from carbohydrates and amino acids, a new model of basic melanoidin skeleton mainly built up from amino-branched sugar degradation products. They indicated that oligo and polysaccharides reacted in the Maillard reaction preferentially as complete molecules at the reducing end under waterfree reaction conditions. The empirical formula of melanoidin has been suggested as $\mathrm{C}_{17-18} \mathrm{H}_{26-27} \mathrm{O}_{10} \mathrm{~N}$. The molecular weight distribution is between 5000 and 40,000. It consists of acidic, polymeric and highly dispersed colloids, which are negatively charged due to the dissociation of carboxylic acids and phenolic groups (Manisankar et al., 2004). Caramel is formed by caramelization process which occurs when sugars are heated in the absence of nitrogen containing compounds. During a caramelization reaction, the sugar initially undergoes dehydration and then condenses or polymerizes into complex molecule. Highly colored, pleasant testing caramel flavour are produces during initial stages, but as the reaction continues, more high molecular weight bodies are produced which are bitter (Yaylayan and Kaminski, 1998).

\section{Physical and chemical properties of Melanoidin}

Melanoidin are dark brown to black colored natural condensation products of sugars and amino acids, they are produced by nonenzymatic browning reactions known as Maillard reactions (Plavsic et al., 2006). Naturally melanoidin are widely distributed in food (Painter, 1998), drinks and widely discharged in huge amount by various agrobased industries especially from distilleries using sugarcane molasses and fermentation industries as environmental pollutants (Kumar and Chandra, 2006). The structure of melanoidin is still not completely understood but it is assumed that it does not have a definite structure as its elemental composition and chemical structures largely depend on the 
nature and molar concentration of parent reacting compounds and reaction conditions as $\mathrm{pH}$, temperature, heating time and solvent system used (Ikan et al., 1990; Yaylayan. and Kaminsky, 1998). Food and drinks such as bakery products, coffee and beer having brown colored melanoidins exhibited antioxidant, antiallergenic, antimicrobial and cytotoxic properties as in vitro studies have revealed that products from Maillard reaction may offer substantial health promoting effects. They can act as reducing agents, metal chelators and radical scavengers (Plavsic et al., 2006). Besides, these healthpromoting properties, melanoidin also have antioxidant -properties, which render them toxic to many microorganisms such as those typically present in wastewater treatment systems (Kumar et al., 1997). The resistance of melanoidin to degradation is apparent from the fact that these compounds escape various stages of wastewater treatment plants and finally enters into the environment.

\section{Melanoidin formation pathway}

The formation of melanoidins is the result of polymerization reactions of highly reactive intermediates formed during Maillard reaction. A wide range of reactions takes place, including cyclizations, dehydrations, retroaldolizations, rearrangements, isomerizations and further condensations, which lead to the formation of brown nitrogenous polymers and copolymers, known as Melanoidin. The molecular weight of colored compounds increases as browning proceeds. The complexity of Maillard reaction has been extensively studied during recent years and new important pathways and key intermediates has been established. Melanoidin are recognized as being acidic compounds with charged nature with increasing reaction time and temperature, the total carbon content increases, thus promoting the unsaturation of the molecules. The color intensity increases with the polymerization degree. The degree of browning, usually measured via absorbance at $420 \mathrm{~nm}$, is often used to follow the extent of Maillard reaction. Hayase et al., (1986) reported the formation of a C3 sugar fragment in early Stages of browning reaction between sugar and amines or amino acids, which was identified as methylglyoxal dialkylamine. It has been suggested that marine humic and fulvic acids are formed by the condensation of sugars with amino acids or proteins via Maillard reaction. Further, the results indicate that various heterocyclic moieties are the main building blocks of humic substances rather than aromatic benzenoid structures (Ikan et al., 1992). Hayashi and Namiki (1986) have also observed that C3 imine formation followed the pattern of $\mathrm{C} 2$ imine formation, and was well correlated to decrease in the amount of glucosylamine and an increase in the formation of Amadori products. Reaction of Amadori products with n-butylamine rapidly produced C3 compound in a manner similar to that of glucose-n-butylamine system. These results indicated the possibility of participation of Amadori products in the formation of C3 compound. In spite of large research work done on the Maillard reaction, many parts as mechanism of melanoidin formation at later final stages of Maillard reaction are still obscure. However, the proposed mechanisms reviewed above present a clear picture of melanoidin formation through Maillard amino-carbonyl reaction.

\section{Structure of melanoidin polymer}

The elucidation of the chemical structure of melanoidin is difficult due to the complexity of the Maillard reaction. The structure is useful for explaining the great increase of the reductone content of melanoidin on heat treatment under anaerobic conditions. However, changing reaction conditions play an important role in the fundamental structure 
of melanoidin. This means that it cannot be assumed that melanoidin have a regular composition with repeating units. The basic structure is formed by $\alpha$-dicarbonyl Maillard reaction intermediates, partially branched by amino compounds and with many reactive centers that make possible further decarboxylation and dehydration reactions. The structure of the real melanoidin is likely to be a result of different reactions from the basic framework. Yaylayan and Kaminsky (1998) isolated a brown nitrogen-containing polymer formed in the Maillard mixture. This polymer exhibited a strong absorption band at $1607 \mathrm{~cm}-1$ in the FTIR spectrum, attributed to extensive conjugation. Pyrolysis of the isolated polymer produced typical Amadori products, such as pyrazines, pyrroles, pyridines and furans. Although the chemical structure of melanoidin is not clearly understood, but some part of the chemical structure of model melanoidin has recently been elucidated by different spectral studies such as $1 \mathrm{H} \mathrm{NMR,} \mathrm{CP-MAS} \mathrm{NMR,} \mathrm{etc.} \mathrm{(Ikan}$ et al 1990).

The chemical have revealed that natural and synthetic melanoidin both have similar elemental (CHON) compositions, spectroscopic properties and electrophoretic mobilities at various $\mathrm{pH}$ values (Ikan et al., 1990). However, the nitrogen contents, acidities and electrophoretic behavior of the polymers all reflect functional group distributions inherited from the amino acids. In spite of these studies, the melanoidin chromophore has not been yet identified. Hence, the chemical structure of the so-called melanoidin is still not clear but probably it does not have a definite one and there exists various types of melanoidins differing in structure depending on parent reactants and reaction conditions as $\mathrm{pH}$, temperature and reaction time. Moreover, it further needs intensive investigations with more refined recent and advanced techniques for the elucidation of chromophore structure to deduce the main skeleton of melanoidin polymer.

\section{Environmental hazards of distillery spent wash}

The production and the characteristics of the spent wash are highly variable and dependent on the feedstock used and various aspects of the ethanol production process. Wash water used to clean the fermenters, cooling water blow down and Oiler water blow down further contribute to its variability. In a Distillery, sources of wastewater are stillage, fermenter and condenser cooling water fermenter wastewater. The liquid residues during the industrial phase of the production of alcohol are: liquor, sugarcane washing water, water from the condensers and from the cleaning of the equipment, apart from other residual water. Distillery effluent has very high biological oxygen demand (BOD), chemical oxygen demand (COD) and high $\mathrm{BOD} / \mathrm{COD}$ ratio.

These melanoidin compounds have antioxidant properties, which render them toxic to many microorganisms such as those typically present in wastewater treatment processes (Kumar et al., 1997). The defiance of melanoidins to degradation is apparent from the fact that these compounds escape various stages of wastewater treatment plants and finally enters into the environment. Apart from melanoidin, the other recalcitrant compounds present in the waste are caramel, variety of sugar decomposition products, anthocyanins, tannins and different xenobiotic compounds. The unpleasant odor of the effluent is due to the presence of putriciable organics like skatole, indole and other sulphur compounds. The molasses effluent that is disposed in canals or rivers produces obnoxious smell. Spent wash disposal into the environment is hazardous and has high 
pollution potential. High COD, total nitrogen and total phosphate content of the effluent may result in eutrophication of natural water bodies (Kumar et al., 1997).

The highly colored components of the effluent can block out sunlight from in rivers, lakes or lagoons which in turn decrease both photosynthetic activity and dissolved oxygen concentration affecting aquatic life. Kumar et al., (1995) evaluated the toxic effect of distillery effluent on common guppy, Lesbistes reticulates and observed remarkable behavioural changes with varying effluent concentration. The coagulation of gill mucous decreased dissolved oxygen consumption causing asphyxiation. Distillery effluent disposed on land is equally hazardous to the vegetation.

It is reported that melanoidins can inhibit seed germination, cause soil manganese deficiency and damage agricultural crops. Raw distillery effluent is highly toxic effect on the growth and germination of Vigna radiata seeds even at low concentration of $5 \%(\mathrm{v} / \mathrm{v})$. Application of distillery effluent to soil without proper monitoring, perilously affects the groundwater quality by altering its physicochemical properties such as color, $\mathrm{pH}$, electrical conductivity (EC), etc. due to leaching down of the organic and inorganic ions (Jain et al., 2005). In a study conducted by Ramana et al., (2002) the germination percent in five crops decreased with increase in concentration of the effluent. The germination was inhibited in all the five crops studied with concentration exceeding $50 \%$.

At the same time, organic wastes contained in distillery effluent are valuable source of plant nutrients especially $\mathrm{N}, \mathrm{P}, \mathrm{K}$ and organic substrates if properly utilized. For instance, distillery effluent in combination with bioamendments such as farm yard manure, rice husk and Brassica residues was used to improve the properties of soil. Recently enhanced production of oyster mushrooms (Pleurotus sp.) using distillery effluent as a substrate amendment have been reported (Pant et al., 2006).

\section{Distillery Effluent Treatment}

Effluent treatment methods aim at the removal of unwanted compounds in wastewater for safe discharge into environment. This can be achieved by using physical, chemical and biological treatment of distillery effluent is either aerobic or anaerobic but in most cases a combination of both is used physical treatment methods such as membrane filtration processes (nanofiltration, reverse osmosis, electro-dialysis) and adsorption techniques are used where as in chemical treatment methods such as coagulation or flocculation are used is found in wastewaters released from various agrobased industries as sugarcane molasses based distillery and fermentation industries and keeping in view the hazardous nature of melanoidin, its chemical and microbial degradation has been attempted to reduce its pollution load and also to characterize its chemical structure so that better strategies could be made for its degradation and decolourization.

\section{Physico-chemical treatment technologies for distillery effluent}

Removal of melanoidin from distillery effluent has been attempted, but with limited success so far (Sirianuntapiboon et al., 2004). Physiochemical treatment processes such as adsorption, oxidation process, coagulation and flocculation have been used for removal of melanoidin from treated effluent. However, these processes still have disadvantages due to the high operation cost, high consumption of chemical agent, fluctuation of color removal efficiency, high volume of solid 
waste produced, formation of hazardous byproducts and intensive energy requirements.

\section{Adsorption}

Activated carbon is a well-known adsorbent due to its extended surface area, microporus structure, high adsorption capacity and high degree of surface reactively. Among the physicochemical treatment methods, adsorption on activated carbon is widely employed for removal of color and specific organic pollutant. Bernardo et al., (1997) investigated decolourization of synthetic melanoidin using commercially available activated carbon as well as activated carbon produced from sugarcane, bagasse. The adsorptive capacity of the different activated carbons was found to be quite comparable. Almost complete decolourization (>99\%) was obtained with $70 \%$ of the eluted sample, which also displayed over 90\% BOD and COD removal. Adsorption by commercially available powered activated carbons resulted in only $18 \%$ color removal combined treatment using coagulation-flocculation with polyelectolyte followed by adsorption resulted in almost complete decolourization. Low cost adsorbents such as pyorchar (activated carbon both in granular and powdered form, manufactured from paper mill sludge) and bagasse flyash have also been studied for this application.

However, to achieve the same level of color removal, larger doses of the indigenously prepared powdered and granular pyorchar were required in comparison to commercial activated carbon. Since the bagasse flyash has high carbon content and the adsorbed organic material further increases its heating value, the spent adsorbent can be used for making fire briquettes. Yet another adsorbent that has been examined is the natural carbohydrate polymer chitosan derived from the exoskeleton of crustaceans.

\section{Coagulation and flocculation}

Coagulation is the destabilization of colloids by neutralizing the forces that keep apart. The optimum dosage of lime was found to be 10 $\mathrm{g} / \mathrm{l}$ resulting in $82.5 \% \mathrm{COD}$ removal and $67.6 \%$ reduction in color in a 30 min period. The treatment resulted in around $87 \%$ decolourization for biodigested effluents; however, an excess of flocculent hindered the process due to increase in turbidity and total organic carbon (TOC) content. $\mathrm{FeCl}_{3}$ and $\mathrm{A} \mathrm{Cl}_{3}$ were also tested for decolourization of biodigested effluent and showed similar removal efficiencies.

About $93 \%$ reduction in color and $76 \%$ reduction in TOC were achieved when either $\mathrm{FeC}_{1}$ or $\mathrm{A} 1 \mathrm{C} 1_{3}$ was used alone. The process was independent of chloride and sulfate on concentration but was adversely affected by high fluoride concentration. However in the presence of high flocculent concentration (40 $\mathrm{g} / \mathrm{l}$ ), addition of $30 \mathrm{~g} / 1 \mathrm{CaO}$ enhanced the decolourization process resulting in $93 \%$ color removal. This was attributed to the ability of calcium ions to destabilize the negatively charged melanoidins; further, formation of calcium fluoride ( $\mathrm{CaF} 2)$ also precipitates the fluoride ions. Almost complete color removal (98\%) of biologically treated distillery effluent has been reported with conventional coagulants such as ferrous sulfate, ferric sulfate and alum under alkaline conditions (Pandey et al., 2003). The best results were obtained using Percol 47, a commercial organic anionic polyelectrolyte, combination with ferrous sulfate and lime. The combination resulted in $99 \%$ reduction in color and 87 and $92 \%$ reduction in COD and BOD, respectively. Coagulation studies on distillery effluent after anaerobic-aerobic treatment have also been conducted using bleaching powder followed by aluminum sulfate. Non-conventional coagulants namely wastewater from an iron pickling industry 
which is rich in iron and chloride ions and titanium ore processing industry containing significant amounts of iron and sulfate ions have also been examined (Pandey et al., 2003). The iron pickling wastewater gave better results with $92 \%$ COD removal, combined with over $98 \%$ color removal. Though the titanium processing wastewater exhibited similar color removal levels, the COD and BOD reductions were perceptibly lower.

\section{Oxidation process}

Ozone destroys hazardous organic contaminants and has been applied for the treatment of dyes, phenolics, pesticides, etc. (Pandey et al., 2003). Oxidation by ozone could achieve $80 \%$ decolourization for biologically treated spent wash with simultaneous $15-25 \%$ COD reduction. It also resulted in improved biodegradability of the effluent. However, ozone only transforms the chromophore groups but does not degrade the dark colored polymeric compounds in the effluent (Pandey et al., 2003). Similarly, oxidation of the effluent with chlorine resulted in $97 \%$ color removal but the color reappeared after a few days. Ozone in combination with $\mathrm{UV}$ radiation enhanced spent wash degradation in terms of COD; however, ozone with hydrogen peroxide showed only marginal reduction even on a very dilute effluent (Beltran et al., 1997). Sonication of distillery wastewater is a pretreatment step to convert complex molecules into a more utilizable form by cavitation. Samples exposed to $2 \mathrm{~h}$ ultrasound pretreatment displayed $44 \%$ COD removal after $72 \mathrm{~h}$ of aerobic oxidation compared to $25 \%$ COD reduction shown by untreated samples.

A combination of wet air oxidation and adsorption has been successfully used to demonstrate the removal of sulfates from distillery wastewater. The wastewater was applied from the top of the reactor and air was supplied at the rate of $1.0 \mathrm{~L} / \mathrm{min}$. The treatment removed commercially available powdered activated carbons resulted in only $18 \%$ color removal; however, combined treatment using coagulation-flocculation with polyelectrolyte followed $57 \%$ COD, $72 \%$ BOD, $83 \%$ TOC and 94\% sulfates. Wet air oxidation has been recommended as part of a combined process scheme for treating anaerobically digested spent wash. The postanaerobic effluent was thermally pre-treated at $150^{\circ} \mathrm{C}$ under pressure in the absence of air. This was followed by soda-lime treatment, after which the effluent underwent a 2 hour wet oxidation at $225^{\circ} \mathrm{C}$. $95 \%$ color removal was obtained in this scheme.

Another option is photo catalytic oxidation that has been studied using solar radiation and $\mathrm{TiO}_{2}$ as the photo catalyst. Use of $\mathrm{TiO}_{2}$ was found to be very effective as the destructive oxidation process leads to complete mineralization of effluent to $\mathrm{CO}_{2}$ and $\mathrm{H}_{2} \mathrm{O}$. Up to $97 \%$ degradation of organic contaminants was achieved in $90 \mathrm{~min}$. Combination of electron beam and Coagulation treatment of distillery slops from distilleries processing grain, potato, beet and some other plant materials. Humic compounds and lignin derivatives constitute the major portion of this dark brown wastewater. The distillery wastewater was diluted with municipal wastewater in the ratio of 3:4, irradiated with electron beam and then coagulated with $\mathrm{Fe}_{2}\left(\mathrm{SO}_{4}\right)_{3}$. The optical absorption in UV region was decreased by 65 $70 \%$ after this treatment. The cost was found to be less than the existing method wherein the effluent was transported about $20 \mathrm{~km}$ via pipeline to a facility for biological treatment followed by sedimentation. The treatment cost was $0.45-0.65 \mathrm{US} \$ / \mathrm{m}^{3}$ which dropped to $0.25 \mathrm{US} \$ / \mathrm{m}^{3}$ using combined electronic-beam and coagulation method. 


\section{Biological/microbial degradation}

Microorganisms (bacteria/fungi/ actinomycetes) due to their inherent capacity to metabolize a variety of substrate have been utilized since long back for biodegradation of complex, toxic and recalcitrant compounds which cause severe damage to environment. Thus, these organisms have been exploited for biodegradation and decolourization of melanoidin pigment present in industrial wastes especially from distillery and fermentation industry.

\section{Anaerobic treatment}

The high organic content of molasses wastewater makes anaerobic treatment attractive in comparison to direct aerobic treatment. Anaerobic digestion is viewed as a complex ecosystem in which physiologically diverse groups of microorganisms operate and interact with each other in a symbiotic, synergistic, competitive or antagonistic association. In the process methane and carbon dioxide are generated (Jain et al., 1990). Molasses wastewater treatment using anaerobic process is a very promising reemerging technology which presents interesting advantages as compared to classical aerobic treatment. It produces very little sludge, requires less energy and can be successfully operated at high organic loading rates; also, the biogas thus generated can be utilized for steam generation in the boilers thereby meeting the energy demands of the unit. Further, low nutrient requirements and stabilized sludge production are other associated benefits (Singh and Nigam 1995). However, the performance and treatment efficiency of anaerobic process can be influenced both by inoculum source and feed pretreatment. These processes have been sensitive to organic shock loadings, low $\mathrm{pH}$ and showed slow growth rate of anaerobic microbes resulting in longer hydraulic retention times (HRT). This often results in poor performance of conventional mixed reactors. In order to solve the Problems, several high rate configurations have been developed for treating soluble wastewater at relatively shorter HRTs.

Anaerobic lagoons are the simplest choice for anaerobic treatment of molasses wastewater. The conventional digesters such as continuous stirred tank reactors (CSTR) are the simplest form of closed reactors with gas collection. Treatment of molasses wastewater in CSTR has been reported in single as well as biphasic operations, resulting in $80-90 \%$ COD reduction within a period of 10-15 days (Painter 1998). Treatment of distillery waste using batch reactors has not been widely attempted. Treatment of winery wastewater was investigated using an anaerobic sequencing batch reactor. In fixed film reactors, the reactor has a biofilm support structure (media) for biomass attachment. Fixed film reactor offers the advantages of simplicity of construction, elimination of mechanical mixing, better stability even at higher loading and capability to withstand toxic shock loads. The upflow anaerobic sludge blanket (UASB) process has been successfully used for the treatment of various types of wastewater (Nataraj et al., 2006). UASB reactor systems belong to the category of high rate anaerobic wastewater treatment and hence it is one of the most popular and extensively used reactor designs for treatment of distillery wastewaters globally. The success of UASB depends on the formation of active and settleable granules (Adikane $e t$ al., 2006). In anaerobic fluidized bed reactor (AFB), the medium which support bacteria attachment and growth is kept in the fluid state by drag forces exerted by the up flowing wastewater. The media used are small particle size sand, activated carbon, etc. In the fluidized state, each medium provides a large surface area for biofilm formation and 
growth. It enables the attainment of high reactor biomass hold-up and promotes system efficiency and stably.

\section{Aerobic treatment}

Anaerobically treated distillery wastewater still contains high concentrations of organic pollutants and then cannot be discharged directly. The partially treated spent wash has high BOD, COD and suspended solids. It can reduce the availability of essential mineral nutrients by trapping them into immobilized organic forms, and may produce phytotoxic substances during decomposition. Stringent regulations on discharge of colored effluent impede direct discharge of anaerobically treated effluent (Eusibio et al., 2004). Therefore, aerobic treatment of sugarcane molasses wastewater has been mainly attempted for the decolourization of the major colorant, melanoidin, and for reduction of the COD and BOD. A large number of microorganisms such as bacteria (pure and mixed culture), cyanobacteria, yeast and fungi have been isolated in recent years and are capable of degrading melanoidins and thus decolorizing the molasses wastewater.

\section{Activated sludge process}

The most common wastewater treatment is the activated sludge process where in research efforts are targeted at improvements in the reactor configuration and performance. For instance, aerobic sequencing batch reactor (SBR) was reported to be a promising solution for the treatment of effluents originating from small wineries. The treatment system consisted of a primary settling tank, an intermediate retention trough, two storage tanks and an aerobic treatment tank. A start up period of 7 days was given to the aerobic reactor and the system resulted in 93\% COD and 97.5\% BOD removal. The activated sludge process and its variations utilize mixed cultures. To enhance the efficiency of aerobics systems, several workers have focused on the treatment by pure cultures. Though aerobic treatment like the conventional activated sludge process is presently practiced by various molasses-based distilleries and leads to significant reduction in COD, the process is energy demanding and the color removal is still unsatisfactory.

Biocomposting is a method of activated bioconversion through the aerobic pathway, whereby heterotrophic microorganisms act on carbonaceous materials depending on the availability of the organic source and the presence of inorganic materials essential for their growth. Composting is particularly effective in converting the wet materials to a usable form thereby stabilizing the organic materials and destroying the pathogenic organisms in addition to significant drying of the wet substrates. In the composting process, under aerobic conditions, thermophilic biodegradation of organic wastes at 40-60\% moisture content occurs to form relatively stable, humus-like materials.

\section{Phytoremediation}

Phytoremediation of effluents is an emerging low cost technique for removal of toxicants including metals from industrial effluents and is still in an experimental stage. Aquatic plants have excellent capacity to reduce the level of toxic metals, BOD and total solids from the wastewaters (Kumar and Chandra, 2004). After a pretreatment in the two first cells the effluent was channeled to cells three and four which contained plants Typha latipholia and Phragmites karka. This treatment eventually led to $64 \%$ COD, $85 \%$ BOD, $42 \%$ total solids and $79 \%$ phosphorus content reduction. Kumar and Chandra (2004) successfully treated distillery effluent in a two stage process involving transformation of recalcitrant coloring components of the 
effluent by a bacterium Bacillus thuringienesis followed by subsequent reduction of remaining load of pollutants by a macrophyte Spirodela polyrrhiza. Phytoremediaion of effluents is an emerging lowcost technique for removal of toxicants including metals from industrial effluents and is still in an experimental stage (Gonzalez et al., 2000).

Cyanobacteria are considered ideal for the treatment of distillery effluent as they, aprt from degrading the polymers also oxygenate water bodies, thus reduce the BOD and COD levels. Marine cyanobacteria such as Oscillatoria boryna have also been reported to degrade melanoidins due to the production of $\mathrm{H}_{2} \mathrm{O}_{2}$, hydroxyl, per hydroxyl and active oxygen radicals, resulting in the decolourization of the effluent (Kalavathi et al., 2001). Patel et al., (2001) have reported $96 \%, 81 \%$ and $26 \%$ decolourization of distillery effluent through bioflocculation by Oscillatoria sp., Lyngbya sp., and Synechocystis sp., respectively.

\section{Fungal degradation of mealnoidin pigment}

Fungi, due to their characteristic morphology (i.e. developed hyphae/mycelium) have excellent adsorption property. These also possess well developed enzymatic system to breakdown complex substrates to derive metabolic energy. Due to such unique features, fungi have been widely exploited for the degradation and decolorization of melanoidin containing wastewater. Watanabe et al., (1982) obtained significant melanoidin decourising activity (MDA) with Coriolus sp. They reported a decrease of $77 \%$ in darkness of melanoidin solution $(0.5 \% \mathrm{v} / \mathrm{v})$ under the condition at $30^{\circ} \mathrm{C}$ for two weeks. Similarly, Aoshima et al., (1985) had screened about 23 genera, 30 strains belonging to white and brown rot fungi for melanoidin decolorization and recorded greater variation in melanoidin decourization activity in various white-rot fungi e.g. Coriolus hirsutus, Coriolus versicolor Ps4a, Fomitopis, Cystisina, Irpex lacteus Ps8a, Lenzites betulina L5b etc. According to them Coriolus versicolor Ps4a showed highest activity, a decolourization yield of approximately $80 \%$ under the optimal conditions. They also reported that production of MDA by $C$. versicolor was almost completely coincident with the growth of mycelia and was mainly due to intracellular enzymes and induced by the molasses melanoidin pigment. Ohmomo et al., 1985 had studied the continous decolourization of molasses waste treated by means of methane fermentation and activated sludge with the mycelia of Coriolus versicolor under both free cell and immobilized conditions. They attained a decolourization of approximately $75 \%$.

\section{Bacterial Decolourization of Melanoidin Pigment}

The reports on the decolourization of melanoidin polymer by bacterial strains are very recent. Due to versatility in the nature of nutrient utilisation, bacteria are capable to degrade different xenobiotic compounds including melanoidin polymer. Ohmomo et al., (1988) screened some facultative anaerobes with melanoidin decolourising activity (MDA). They reported that strain WNS showed high and stable MDA and was identical to Lactobacillus hilgardii. The decolourization yield of this strain under optimum conditions was $28 \%$. However, the immobilization of cells within Calcium alginate gels improved the decolourization yield to $40 \%$. According to these researchers unlike Ascomycetes and Basidiomycetes, this strain decolourised smaller molecular weight fractions of melanoidins quickly. They also reported the MDA of this strain towards various synthetic melanoidins (e.g. from glucose and glycine; glucose and valine etc.). 
The MDA of this strain was found quiet different from that of Basidiomycetes. Investigations on the continuous decolourization of molasses wastewater (MWW) by using the immobilized Lactobacillus hilgardii W- NS cells have shown the maximal decolourization yield $(90 \%)$ in presence of glucose $(1 \% \mathrm{w} / \mathrm{v})$ at $45^{\circ} \mathrm{C}$. Further, the successive decolourization of MWW with the recycling of immobilized cells was recorded more than $90 \%$ of the maximal decolourization that was maintained for one month when peptone $(0.05 \%)$ was added to MWW. However, on adjusting the medium $\mathrm{pH}$ to neutral $(\mathrm{pH}$ 7.3) compared with (5.0) has slowed down the decrease in the decolourization yield. Kumar et al., (1998) reported that two aerobic bacterial cultures LAI and D-2 showed the highest decolourization (36.5 and 32.5\%) and COD reduction (41 and 39\%) respectively under optimum conditions. They suggested that the decolourization achieved might be due to the degradation of smaller molecular weight fractions of melanoidin. These investigations have ruled out the possible involvement of manganese dependent peroxidase and all other lignolytic peroxidases as suggested by previous workers in the decolourization of melanoidin containing molasses spent wash. They suggested that decolourization may have occurred as a result of secondary metabolic reaction resulting from a secondary metabolite. Nevertheless, the actual mechanism of melanoidin degradation according to them remains yet to be confirmed.

\section{Decolourization of distillery effluent by yeast}

Yeast, Citeromyces is most studied organism for treating MWW and high and stable removal efficiencies in both colour intensity and organic matter have been recorded (Sirianuntapiboon et al., 2003). Mohan et al.,
(2009) isolated yeast which was able to reduce the COD of synthetic wastewater by $95 \%$ and $46 \%$ within $24 \mathrm{~h}$ under aerated and non-aerated conditions respectively. Two flocculant strains of yeast, Hansenula fabianii and Hansenula anomala was used for the treatment of wastewater from beet molassesspirits production and achieved $25.9 \%$ and $28.5 \%$ removal of TOC respectively from wastewater without dilution (Moriya et al., 1990). Dilution of wastewater was not favorable for practical treatment of wastewater due to the lower treatment time and higher energy cost. Color removal from MSW using terrestrial white-rot fungi was shown to be Mn-P dependent in Phanerochaete chrysoporium (Dehorter and Blondeau, 1993) and laccase dependent in Trametes versicolor (Gonzales et al., 2008). The process was sorbose oxidase and glucose oxidase-depenent in mitosporic fungi Aspergilllus fumigates (Miranda et al., 1996) and A. oryzae (Sirianuntapiboon et al., 1998).

\section{Fungal Consortium Treatment}

During the last two decades, several attempts have been made to investigate the possibility of using cell immobilization in the technology of aerobic wastewater treatment. Early experiments were restricted to the use of selected pure cultures immobilized on solid supports for the degradation of specific toxic compounds (Anselmo et al., 1985). Later, immobilized consortia of two or more selected strains were employed. Jet loop reactors (JLR) the efficiency of which has already been shown in both chemical and biological processes have also been evaluated for the aerobic treatment of winery wastewater (Petruccioli et al., 2002). COD removal efficiency higher than $90 \%$ was achieved with an organic load of the final effluents that ranged between 0.11 and $0.3 \mathrm{~kg}$ COD $\mathrm{m}^{3}$. Most isolates belong to the genus Pseudomonas and the yeast Saccharomyces 
cerevisiae. Later, Eusibio et al., (2004) reported the operation of a JLR for the more than one year treating winery wastewater collected in different seasons and achieved an average COD removal efficiency of $80 \%$. JLR have higher oxygen transfer rates at lower energy costs. They also observed Bacillus apart from Pseudomonas and the yeast Saccharomyces cerevisiae.

\section{Immobilized bioreactors}

Cells of Phanerochaete chrysosporium immobilized in calcium-alginate beads resulted in a much more rapid decolourzation of MSW than did free cells (Fahy et al., 1997). Maximum color reduction occurred between 0 and 2 days. However, the color eliminated was reduced from $85 \%$ with free cells to $59 \%$ with immobilized cells after 10 days. The immobilized Coriolus versicolor on nylon cubes in a packed-bed bioreactor eliminated the COD of the pretreated spent wash by a further $50.3 \%$ reaching a total reduction of $77 \%$ (Fitz Gibbon et al., 1995). Only 4\% color was eliminated and this was due primarily to absorption onto the fungal mycelia rather than enzymatic oxidation. It is possible to bioremediate such spent waste using a multistage treatment process with an initial treatment with Geotrichum candidum. In another study it was shown that immobilized Flavodon flavus in $1 \mathrm{~cm}^{3}$ of polyurethane foam could be used effectively for three consecutive cycles of decolourization of fresh $10 \%$ MSW (Raghukumar et al., 2004). The fungus also removed about $98 \%$ of the toxicity of the MSW using an estuarine fish, Oreochromis mossambicus. Penicillium decumbens, Penicilium lignorum, and Aspergillus niger produced maximum decolourization of the beet molasses alcoholic fermentation wastewater on the fourth day of treatment (Jimenez et al., 2003).
In conclusion, the waste water contamination is a major crisis that is increasing day by day. The conventional methodologies fail to remediate certain contaminants from the waste water. The melanoidin contamination within the waste water is hard to remove and toxic to all the living beings. The ability of microbes to utilize the complex melanoidin as source of carbon can resolve the problem of melanoidin contamination in soil. The microbes mainly bacteria, fungi and yeast can be exploited widely for the bioremediation of melanoidins in contaminated water.

\section{References}

Adikane, H.V., Dange, M.N., Salvakumari, K., 2006. Optimization of anaerobically digested distillery molasses spent wash decolourization using soil as inoculums in the absence of additional carbon and nitrogen source. Bioresour. Technol. 97, 2131-2135.

Anselmo, A.M., Mateus, M., Cabral, J.M.S., Novais, J.M., 1985. Degradation of phenol by immobilized cells of Fusarium flocciferum. Biotechnol. Lett. 7, 889-894.

Aoshima, I., Tozawa, Y., Ohmomo, S., Ueda, K., 1985. Production of Decolorizing Activity for Molasses Pigment by Coriolus versicolor Ps4a. Microbiol. Ferment. Technol. 49, 2041-2045.

Bernado, E.C., Egashira, R., Kawasaki, J., 1997. Decolourization of molasse wastewater using activated carbon prepared from cane bagasse. Carbon 35, 1217-1221.

Bustamante, M.A., Paredes, C., Moral, R., Moreno-Caselles, J., Perez-Espionosa A., Perez-Murcia A., 2005. Uses of winery and distillery effluents in agriculture: Characterization of Nutrient and hazardous components. Water Sci. Technol. 51, 145-151.

Collins, G., Foy C., McHugh S., Maho, T., 
O'Flaherty, V., 2005. Anaerobic biological treatment of phenolic wastewater at $15-18^{0} \mathrm{C}$. Water Res. 39, 1614-1620.

Dehorter, B., Blondeau, R., 1993. Isolation of an extracellular Mn-dependent enzyme mineralizing melanoidins from the white rot fungus Trametes versicolor. FEMS Microbiol. Lett. 109, 117-122.

Eusibio, A., Petruccioli, M., Lageiro, M., Fedrici F., Duarte, J.C., 2004. Microbial characterization of activated sludge in jet-loop bioreactors treating winery wastewaters. J. Ind. Microbiol. Biotechnol. 31, 29-34.

Fahy, V., FitzGibbon, F.J., McMullan, G., Singh, D., Marchant, R., 1997. Decolourization of molasses spent wash by Phanerochaete chrysosporium. FEMS Biotechnol. Lett. 19, 97-99.

FitzGibbon, FJ., Nigam, P., Singh, D., Marchant, R., 1995. Biological Treatment of distillery waste for pollution-remediation. J. Basic Microbiol. 35, 293-301.

Frontline, 2012. Sugar decontrol and its implications. DATA CARD Oct. 19, 130-131.

Ghosh, M., Ganguli, A., Tripathi, A.K., 2002. Treatment of anaerobically digested distillery spentwash in a two-stage bioreactor using Pseudomonas putida and Aeromonas sp. Process Biochem. 7, 857-862.

Godshall, M.A., 1999. Removal of colorants and polysaccharides and quality of white sugar. In: Proceedings of sixth International Symposium Organized by Association Andrew van Hook (AvH), 28-35.

Gonzalez, T., Terron, M.C., Yague, S., Zapico, E., Galletti, G.C., Gonzalez, A.E., $2000 . \quad$ Pyrolysis/ gaschromatography/ mass spectrometry monitoring of fungal biotreated distillery wastewater using Trametes sp.
I-62 (CECT 20197). Rapid Commun. Mass Spectrom. 14, 1417-1424.

Hayase, F., Kim, S.B., Kato, H., 1986. Analyses of the chemical structures of melanoidins by 13C NMR, 13C and 15N CP-MAS NMR spectrometry. Agri. Biol. Chem. 50, 1951-1957.

Ikan, R., Doresey T., Kaplan, I.R., 1990. Characterization of natural and synthetic humic substances (melanoidins) by stable carbon and nitrogen isotope measurements and elemental compositions. Anal. Chim. Acta. 232, 11-18.

Jain, N., Minocha, A.K., Verma, C.L., 2002. Degradation of predigested distillery effluent by isolated bacterial strains. Ind. J. Exp. Bot. 40, 101-105.

Jimenez, AM., Borja, R., Martin, A., 2003. Aerobic-anaerobic biodegradation of beet molasses alcoholic fermentation wastewater. Process Biochem. 38, 1275-1284.

Kalavathi, D.F., Uma, L., Subramanian, G., 2001. Degradation and metabolization of the pigment-melanoidin in distillery effluent by the marine Cyanobacterium Oscillatoria boryana BDU 92181. Enzyme Microb. Technol. 29, 246-251.

Kanimozhi， R., Vasudevan, N., 2010. An overview of wastewater treatment in distillery industry. Int. J. Environ. Eng. 2, 159-184.

Keyser, M.R.C., Witthuhn, L.C., Ronquest, Britz, T.J., 2003. Treatment of winery effluent with upflow anaerobic sludge blanket (UASB) granular sludges enriched with Enterobacter sakazakii. Biotechnol. Lett. 25, 1893-1898.

Kitts, D.D., Wu, C.H., Stich, H.F., Powrie, W.D., 1993. Effects of glucose glycine Maillard reaction products on bacterial and mammalian cells mutagenesis. J. Agri. Food. Chem. 41, 2353-2358.

Kort, M.J., 1979. Colour in the sugar industry. In: de Birch, G.G., Parker, K.J., (Eds.) 
Science and Technology. Applied Science, London. 97-130.

Manisankar, P., Rani, C., Viwanathan, S., 2004. Effects of halides in the electrochemical treatment of distillery effluent. Chemosphere 57, 961-966.

Miranda, M.P., Benito, G.G., Cristobal, N.S., Nieto, H., 1996. Color elimination from molasses wastewater by Aspergillus niger. 57, 229-235.

Mohan, S., Acharya K.B., Madamwar D., 2009. Treatment technologies and potential applications. J. Hazard. Mater. $163,12-25$.

Morales, F., Jimnez-Perez S., 2001. Free radical scavenging capacity of Maillard reaction products as related to colour and fluorescence. Food Chem. 72, 119125.

Moriya, K., Iefuji, H., Shimoi, H., Sato, S., Tadenuma, M., 1990. Treatment of distillery wastewater discharged from beet molasses-spirits production using yeast. J. Fermen. Bioeng. 69, 138-140.

Natraj, S.K., Hosamani, K.M., Aminabhavi, T.M., 2006. Distillery wastewater treatment by the membrane based nanofiltation and reverse osmosis. Water Res. 40, 2349-2356.

Ohmomo, S., Aoshima, I., Tozawa, Y., Sakurada, N., Ueda, K., 1985. Purification and Some Properties of Melanoidin Decolorizing Enzymes, PIII and P-IV, from Mycelia of Coriolus versicolor Ps4a. Agric. Biol. Chem. 49, 2047-2053.

Painter, T.J., 1998. Carbohydrate polymers in food preservation: an integrated view of the Maillard reaction with special reference to discoveries of preserved food in Sphagnum-dominated peat bogs. Carbohydrate Polym. 36, 335347.

Pant, D., Adholeya, A., 2007. Identification, ligniolytic enzyme activity and decolourization potential of two fungi isolated from a distillery effluent contaminated site. Water Air Pollut. $183,165-176$.

Petruccioli, M., Duarte, J.C., Eusebio, A., Federici, F., 2002. Aerobic treatment of winery wastewater using a jet-loop activated sludge reactor. Process Biochem. 37, 821-829.

Plavsic, M., Cosovic, B., Lee, C., 2006. Copper complexing properties melanoidin and marine humic material. Sci. Total Environ. 366, 310-319.

Raghukumar, C., Mohandass, C., Kamat, S., Shailaja, M.S., 2004. Simultaneous detoxification and decolorization of molasses spent wash by the immobilized white-rot fungus Flavodon flavus isolated from marine habitat. Enzyme Microb. Technol. 35, 197-202.

Ramana, S., Biswas, A.K., Singh A.B., 2002. Effect of distillery effluent on some Physiological aspects of maize. Biores. Technol. 84, 295-297.

Satyawali, Y., Balakrishnan M., 2007. Removal of color from biomethanated distillery spent wash by treatment with activated carbons. Biores. Technol. 98, 2629-2635.

Satyawali Y., Balakrishan, M., 2008. Wastewater treatment in molassesbased distilleries for COD and color removal. J. Environ. Manag. 86, 481497.

Singh, D., Nigam, P., 1995. Treatment and disposal of distillery effluents in India. In: Environmental Biotechnology: Principles and Applications, 735-750.

Subramanian, K.A., Singal, S.K., Saxena, M., Singhal, S., 2005. Utilization of liquid biofuels in automotive diesel engines: an Indian perspective. Biomass Bioenergy 29, 65-72.

Tewari, P.K., Batra, V.S., Balakrishnan M., 2007. Water management initiatives in sugarcane molasses based distilleries in India. Res. Conserv. Recycl. 52, 351- 
367.

Uppal, J. 2004. Water utilization and effluent treatment in the Indian alcohol industry: and overview. In: Tewari, P.K. (Ed.), Liquid Asset, Proceedings of the IndoEU Workshop on Promoting Efficient Water Use in Agro-Based Industries. TERI Press, New Delhi, India, 13-19.

Watanabe, Y., Sugi, R., Tanaka, Y., Hayashida, S., 1981. Enzymatic decolourization of melanoidin by Cariolus sp. No. 20. Microbiol. Ferment. Technol. 46, 1623-1630.

Wedzicha, B.L. Kaputo, M.T., 1992. Melanoidins from glucose and glyeme composition. Characteristics and reactivity towards sulphite-ion. Food Chem. 43, 359-367.

Wilkie, A.C., Riedesel, K.J., Owens, J.M., 2000. Stillage characterization and anaerobic treatment of ethanol stillage from conventional and cellulosic feed stocks. Biomass Bioenergy 19, 63-102.

Yaylayan, V.A., Kaminsky, E., 1998. Isolation and structural analysis of Maillard polymers: Caramel and melanoidin formation in glycine/glucose model system. Food Chem. 63, 25-31.

\section{How to cite this article:}

Ranjan Singh, Tanim Arpit Singh, Trashi Singh, Rajeeva Gaur, Prabash Kumar Pandey, Farrukh Jamal, Shikha Bansal, Laxmi Kant Pandey, Surendra Sarsaiya, Jitendra Nagpure, Saket Mishra, Manogya Kumar Gaur, Priyanka Gupta, Priyanka Uikey, Subhendra K. Patel and Rakhi Patel. 2019. Origin and Remediation of Melanoidin Contamination in Water Sources. Int.J.Curr.Microbiol.App.Sci. 8(02): 1399-1415. doi: https://doi.org/10.20546/ijcmas.2019.802.164 